\title{
Retraction Note: Coastal tourism resource development based on big data mining and environmental sustainability
}

\author{
Yanhong Zhao ${ }^{1}$
}

Published online: 25 November 2021

C) Saudi Society for Geosciences 2021

Retraction Note: Arabian Journal of Geosciences (2021) 14: 1584

https://doi.org/10.1007/s12517-021-07893-8

The Editor-in-Chief and the Publisher have retracted this article because the content of this article is nonsensical. The peer review process was not carried out in accordance with the Publisher's peer review policy. The author has not responded to correspondence regarding this retraction.

The original article can be found online at https://doi.org/10.1007/ s12517-021-07893-8.

Yanhong Zhao

Zhaoyanhong_202105@163.com

1 School of Tourism Management, Henan Finance University, Zhengzhou 451464, Henan, China 